\title{
Plasmonic Zr-Based Metal-Organic Frameworks for Accelerated De-Colorization of Methylene Blue Under LED Light Irradiation
}

\section{LED Işık Işınımı Altında Metilen Mavisinin Hızlandırılmış Renksizleştirilmesi için Plazmonik Zr-esaslı Metal-Organik Çerçeveler}

\author{
Kouroush Salimi ${ }^{\odot}$ \\ Department of Chemical Engineering, Ankara Yildirim Beyazit University, Etlik, Ankara, Turkey.
}

\section{ABSTRACT}

W ell-defined photocatalyst with 3D morphologies have attracted the attention of scientists due to the more accessible reactive surfaces, easy to recover from reaction medium, and low aggregation. Within this scope, photocatalysis based on plasmonic metal-organic frameworks (MOFs) were synthesized and utilized as an alternative reactive platform for visible-light degradation of methylene blue (MB) under green LED irradiation for the first time. In order to reduce the recombination between electron-hole pairs, a stable oxidant, namely sodium persulfate (PS) was employed to accelerate the photocatalytic decolorization of MB. These feasible strategies demonstrated that a bleaching degree of $91 \%$ (i.e., in the presence of PS) within 120 min was achieved compared to the bare Au@UiO-66@Pdop NPs (bleaching degree 31\%). The obtained results from this study highlighted the superior properties of the newly synthesized core-shell Au@UiO-66@Pdop photocatalysts and clearly declared the great potential of the photo-responsive MOFs for organic pollutant degradations as well.

\section{Key Words}

Plasmonic metal organic frameworks (MOFs), visible LED light, photocatalytic decolorization.

\section{öz}

\begin{abstract}
3. boyutlu morfolojiye sahip iyi tanımlanmış fotokatalizörler, daha erişilebilir reaktif yüzeyler, reaksiyon ortamından kolay bir şekilde elde edilebilmeleri ve düşük agregasyona sahip olmalarından dolayı bilim adamlarının dikkatini çekmiştir. Bu kapsamda, plazmonik metal organik çerçeve (MOF’ler) esaslı fotokatalizör sentezlendi ve ilk kez yeşil LED ışık ışınımı aracılığıyla metilen mavisinin (MB) görünür ışık altındaki degradasyonu için alternatif bir reaktif platform olarak kullanılmıştır. Elektron-boşluk çiftleri arasındaki rekombinasyonu azaltarak MB'nin fotokatalitik renksizleştirilmesini hızlandırmak için istikrarlı bir oksidan olan sodyum persülfat (PS) kullanılmıştır. Uygulanan stratejiler aracılığıyla çıplak Au@UiO-66@Pdop NP’lere kıyasla (yıkım derecesi \%31) PS kullanılarak 120 dakika içinde \%91'lik bir degredasyon derecesinin eldesi gösterilmiştir. Bu çalışmadan elde edilen sonuçlar, yeni sentezlenmiş çekirdek kabuk (core-shell) yapısındaki Au@UiO-66@Pdop fotokatalizörünün üstün özelliklerini vurgulamış ve ışık duyarlı MOF'lerin organik kirleticilerin degradasyonu için de mükemmel potansiyelini açık şekilde ortaya koymuştur.
\end{abstract}

\section{Anahtar Kelimeler}

Plazmonik metal-organik çerçeveler (MOF'ler), görünür LED ışık, fotokatalitik renksizleştirme.

Article History: Received: Sep 11, 2019; Revised: Oct 9, 2019; Accepted: Oct 16, 2019; Available Online: Oct 30, 2019. DOI: $\underline{\text { https://doi.org/10.15671/hjbc.618668 }}$

Correspondence to: K. Salimi; Department of Chemical Engineering, Ankara Yildirim Beyazit University, Etlik, Ankara, Turkey.

E-Mail: kouroushsalimi@gmail.com 


\section{INTRODUCTION}

Reran ecently, visible light sensitive photocatalysts (i.e., $\mathrm{GaP}, \mathrm{WO}_{3}, \mathrm{Cds}, \mathrm{ZnS}$, and etc.) have attracted the attention of related communities due to their narrow band gap compared to conventional UV-light responsive $\mathrm{TiO}_{2}$ based materials [1-3]. However, this inorganic photocatalysts showed some drawbacks like low light conversion efficiency, hard desorption/separation from reaction media, as well as strong tendency for agglomeration [4]. This issue places the demand for the fabrication of a new class of photocatalysts with potential application in organic pollutant degradations.

Metal-organic frameworks (MOFs) are a class of porous coordination polymers constructed by strong chemical bonding of metal nodes and organic linkers $[5,6]$. The unique chemical composition and diverse structural and functional features (i.e., large surface area, easy in-pore and surface functionalization) make them an extraordinary material for various applications including carbon dioxide capture, catalyst, separation science, sensing, biomedical, and analytical sciences [7-12]. Owing to the absorption of the irradiated light, MOFs were carried out as a significant photocatalyst for environmental fi- elds $[4,13]$. Xamena et al. reported the application of MOF-5 in photocatalytic degradation of phenols under UV-light irradiation [14]. Das et al. investigated a $\mathrm{Zn}_{4} \mathrm{O}$-containing doubly interpenetrated MOF for photocatalytic degradation of methyl orange using UV or visible light source [15]. More recently, reduced energy demand of photocatalytic degradation processes and optimizing of the photocatalytic parameters increased the use of LED photoreactors [16]. These photoreactors provided high energy efficiency, long lifespan, as well as low power consumption compared to the conventional light sources [16]. In this context, MIL-53 (Fe) was developed for accelerated photocatalytic degradation of acid Orange 7 (AO7) using visible LED light irradiation [16]. They provided an accelerated photocatalytic performance by reducing the charge carrier recombination using persulfate as an oxidant [16].

In this study, plasmonic zirconium-based metal-organic frameworks (Au@UiO-66@Pdop) were utilized for de-colorization of methylene blue $(\mathrm{MB})$ under green LED light irradiation for the first time in the literature. Plasmonic photo-responsive catalyst was synthesized using polydopamine nanoparticles (Pdop NPs) as starting template. Thanks to the catechol groups of the

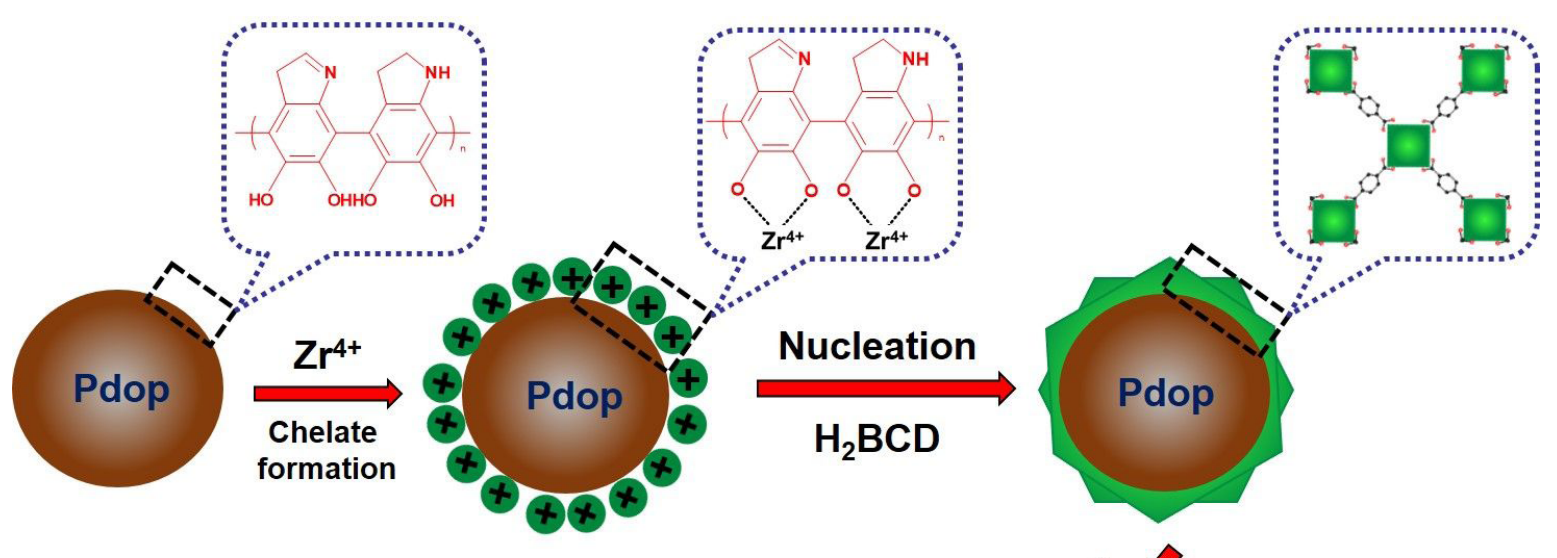

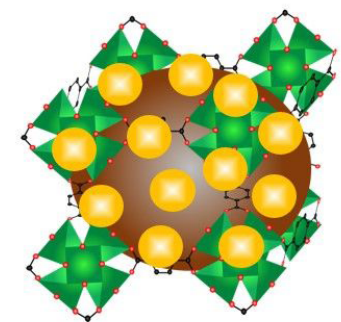

Au@UiO-66@Pdop MOF

\section{Au decoration}

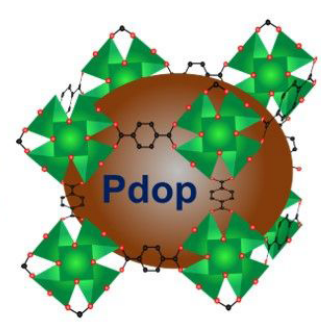

UiO-66@Pdop MOF

Figure 1. Schematic illustration of the synthetic pathway of Au@Uio-66@Pdop MOFs. 

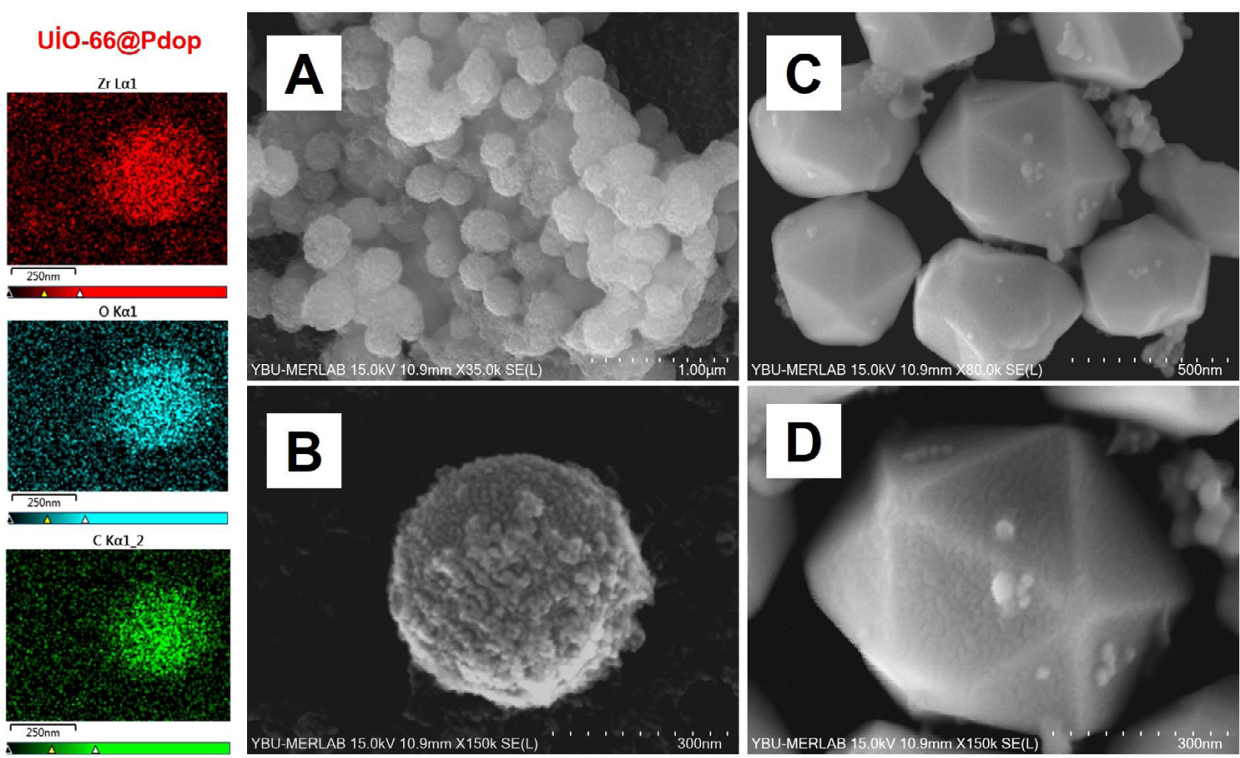

Au@Uio-66@Pdop
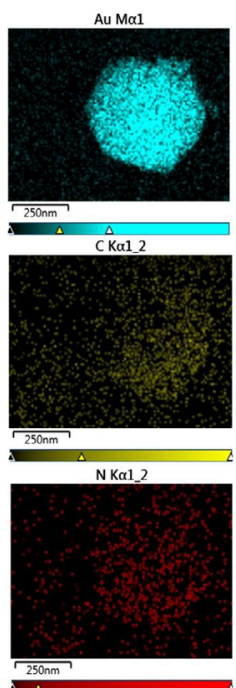

Figure 2. SEM and EDX analysis of A-B) UiO-66@Pdop, and C-D) Au@UiO-66@Pdop NPs.

Pdop, quite stable core-shell catalyst NPs with desired spherical morphologies and good localized surface plasmon resonance (LSPR) properties were obtained. Additionally, a home-made green LED light source was employed to investigate the performance of the photo-responsive Au@UiO-66@Pdop NPs for an efficient decolorization of organic pollutant. An excellent photocatalytic performance was recorded using sodium persulfate (PS) with important reduction in the charge carrier recombination. Finally, the effect of different reaction conditions on the variation of $\mathrm{MB}$ concentration $(\mathrm{C} / \mathrm{CO})$ and reaction time were reported.

\section{MATERIALS and METHODS}

\section{Synthesis Methods}

Polydopamine nanoparticles (Pdop NPs) were synthesized according to the literature with some modifications [17]. Briefly, an aqueous solution containing ammonia (3.5 mL, $2.5 \%)$, ethanol $(2 \mathrm{~mL})$, and DDI water $(6 \mathrm{~mL})$ were stirred at room temperature for $5 \mathrm{~min}$ followed by the addition of dopamine hydrochloride $11 \mathrm{mg}$ in $1 \mathrm{~mL}$ DDI water). The resulting dispersion was stirred at room temperature for $8 \mathrm{~h}$. Finally, Pdop NPs were centrifuged and washed with DDI water several times.

A well-defined core shell structure between Pdop NPs and Zr-based MOFs (UiO-66) was achieved in the presence of metal nodes and organic building blocks [18]. Typically, Pdop NPs (1 mg) were dispersed into $\mathrm{N}-\mathrm{N}$, dimethylformamide (DMF, $10 \mathrm{~mL}$ ) and ultraso- nicated for 10 min using an ice-bath. Then, zirconium chloride $\left(\mathrm{ZrCl}_{4}, 1 \mathrm{mg}\right)$ and 1,4-benzenedicarboxylic acid (H2BDC, $10 \mathrm{mg}$ ) were introduced into the as-prepared solution and stirred at $140^{\circ} \mathrm{C}$ for $100 \mathrm{~min}$. MOF shell coated Pdop NPs (UiO-66@Pdop) were isolated from reaction media and washed with methanol and DDI water, respectively.

For the synthesis of plasmonic Zr-based MOFs (Au@ UiO-66@Pdop), MOF coated Pdop NPs were dispersed into an aqueous solution of chloroauric acid (30 mg, 50 $\mathrm{mL}$ ) and vigorously mixed at $50^{\circ} \mathrm{C}$ for $2 \mathrm{~h}$. Then, the solution was heated to boiling and the boiling was continued for $5 \mathrm{~min}$. Subsequently, an aqueous solution of tri-sodium citrate ( $2 \mathrm{~mL}, 0.035 \mathrm{~g}$ ) was introduced into the as-prepared solution and the boiling was further continued for $30 \mathrm{~min}$. The resulting nanostructures were cooled down to room temperature and finally washed with DDI water for three times using centrifugation method. Finally, Au NPs embedded Zr-based MOFs (Au@UiO-66@Pdop) were kept in DDI water for further usage.

\section{Characterization of Au@UiO-66@Pdop MOFs}

The surface morphology and size distribution of nanostructures were determined by a scanning electron microscope (Hitachi, SU5000, Japan) which is equipped with an Energy Dispersive X-Ray spectrometry (EDX). The surface chemistry of plasmonic MOFs were analyzed using X-ray photoelectron spectroscopy (XPS, Thermo-K-Alpha-Monochromatic high-performance 


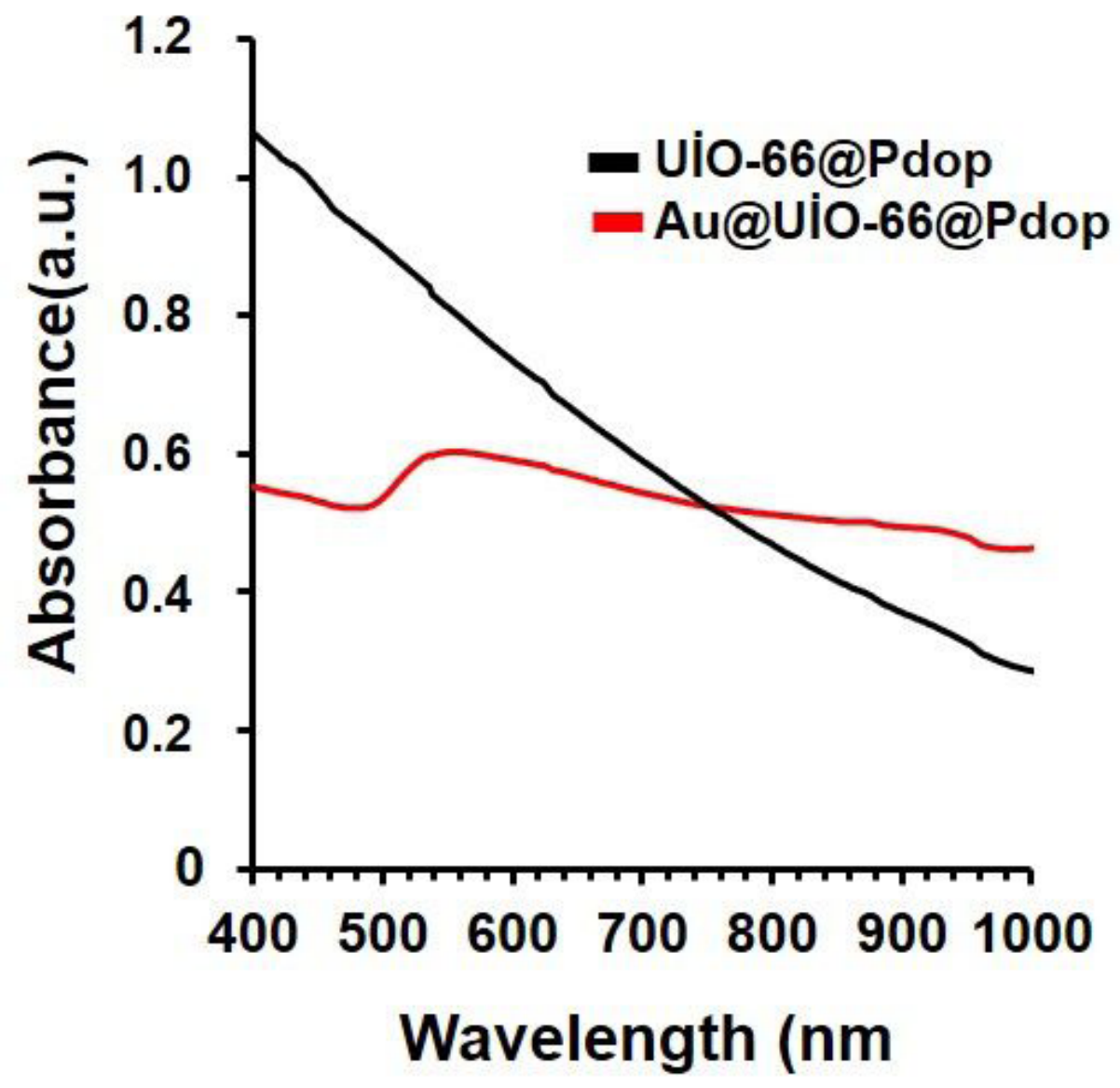

Figure 3. UV-vis spectra of the aqueous solution of UiO-66@Pdop and Au@UiO-66@Pdop NPs.

XPS Spectrometer, source gun: Al K-Alpha at $1.4 \mathrm{kV}$ focus voltage, beam current: $6 \mathrm{~mA})$. The UV-vis measurement of devices was performed by Schimadzu 3600 spectrophotometer.

\section{Photocatalytic Activity Tests}

The photocatalytic degradation of methylene blue (MB) was carried out using a home-made green-LED photoreactor equipped with a cylinder type aluminium which containing 237 LED lamps. Typically, $20 \mathrm{~mL}$ of dye solution $\left(3.125 \times 10^{-5} \mathrm{M}\right)$ containing $20 \mathrm{mg}$ of plasmonic photocatalyst was magnetically stirred in the dark for $30 \mathrm{~min}$ in order to reach an adsorption-desorption equilibrium as well. Then, the light was irradiated onto the solution in which the sampling was carried out in specific time intervals. For this purpose, $2.0 \mathrm{~mL}$ of sample solution was taken from the reactor and centrifuged at 5000 rpm for $5 \mathrm{~min}$. The real-time concentration of MB molecules in the supernatant was measured at $610 \mathrm{~nm}$ using the UV-vis spectrometer. The same procedure was repeated when the PS $(2.0 \mathrm{mM})$ was introduced in the reaction medium.

\section{RESULTS and DISCUSSION}

The synthetic pathway for the fabrication of plasmonic core-shell Au@Uio-66@Pdop MOFs is represented in Figure 1. Firstly, Pdop NPs were synthesized by polymerization of dopamine in alkaline medium using ammonia, ethanol, and DDI water. After that, the one-pot synthesis of well-defined Zr-based MOF shell onto Pdop NPs was carried out using DMF, $\mathrm{H}_{2} \mathrm{BCD}$, and $\mathrm{ZrCl} 4$. The presence of strong diol groups $(-\mathrm{OH})$ onto Pdop NPs led to the enrichment of $\mathrm{Zr}^{4+}$ ions as well as chelate formation while the organic building blocks $\left(\mathrm{H}_{2} \mathrm{BCD}\right)$ initiated the nucleation of UiO-66 MOF. This technique prevented the independent formation of MOFs in the reaction medium. Additionally, once the nucleation of MOF onto Pdop NPS was started, the layer-by-layer shell growth realized without free MOF particles in the reaction medium.Finally, Au@Uio-66@Pdop MOFs were achieved using a simple solution impregnation method, in which Au NPs were successfully embedded into the pores of MOF shell as well. 

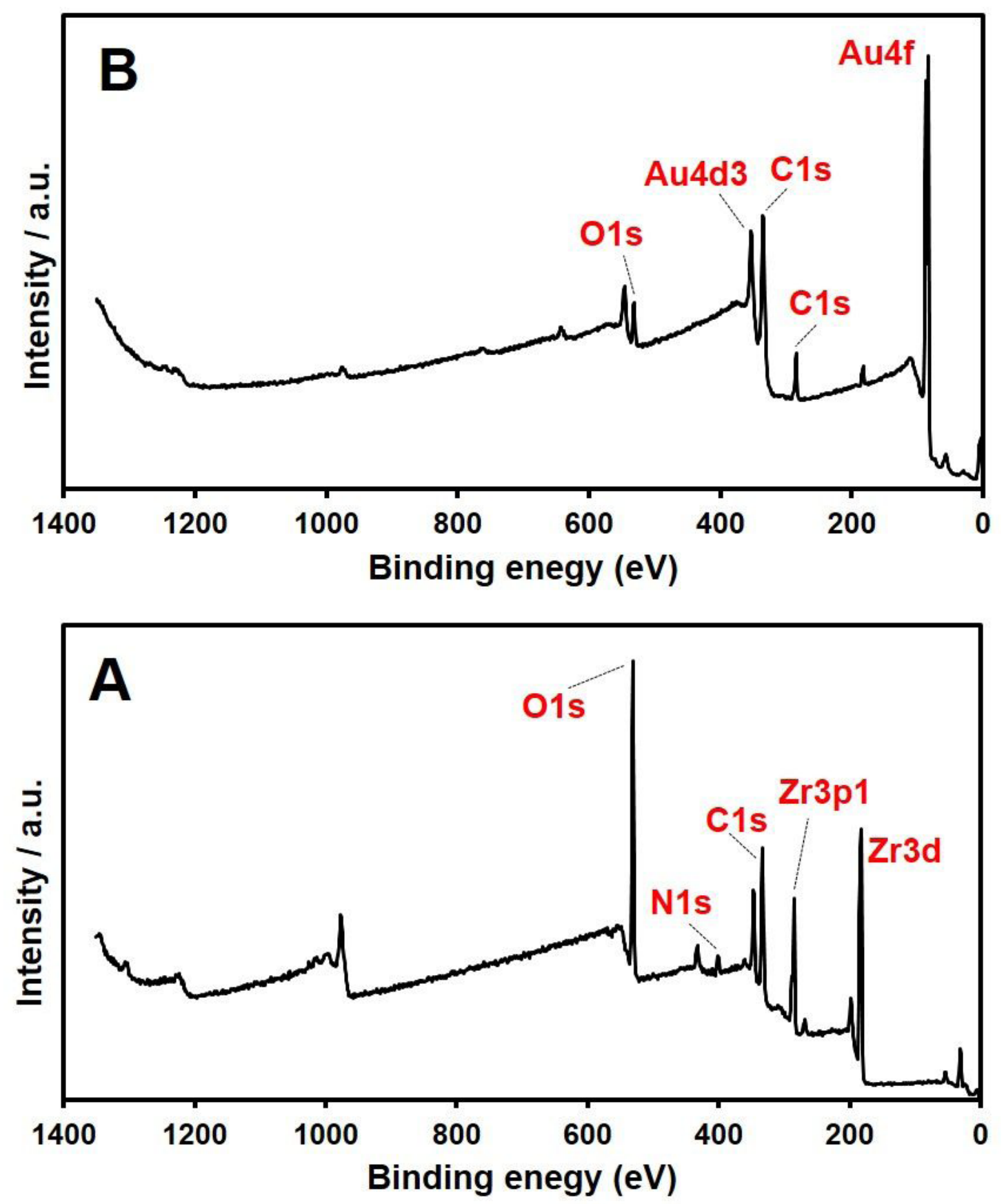

Figure 4.XPS spectra of A) UiO-66@Pdop and B) Au@UiO-66@Pdop NPs.

The SEM images and EDX analysis of the UIO-66@Pdop and Au@UiO-66@Pdop NPs are presented in Figure 2. As seen here, all of the NPs were demonstrated narrow size distribution with no significant change in the spherical morphology of the starting Pdop nanoparticles (Figure $2 \mathrm{~A}$ and $2 \mathrm{~B}$ ). Additionally, Zr-based MOFs were successfully coated onto the Pdop templates without free MOF aggregates (Figure $2 \mathrm{~A}, \mathrm{~B}$ ). Furthermore, the SEM images and EDX mapping of the Au@Uio-66@Pdop
NPs clearly showed that the solution impregnation of $\mathrm{Au}$ as well as Au NPs embedding were also successfully synthesized. Moreover, from the EDX analysis, $\mathrm{Zr}$ L $\alpha 1$ (17.5 Wt\%), O Ka1 (38.9 Wt\%), C Ka1 (43.6 Wt\%), and Au Ma1 (53.5 Wt\%), C Ka1 (42.2 Wt\%), N Ka1 (4.3 Wt\%) elemental compositions related to the vio-66@Pdop and Au@UiO-66@Pdop NPs were achieved with quite clear photographs, respectively. 

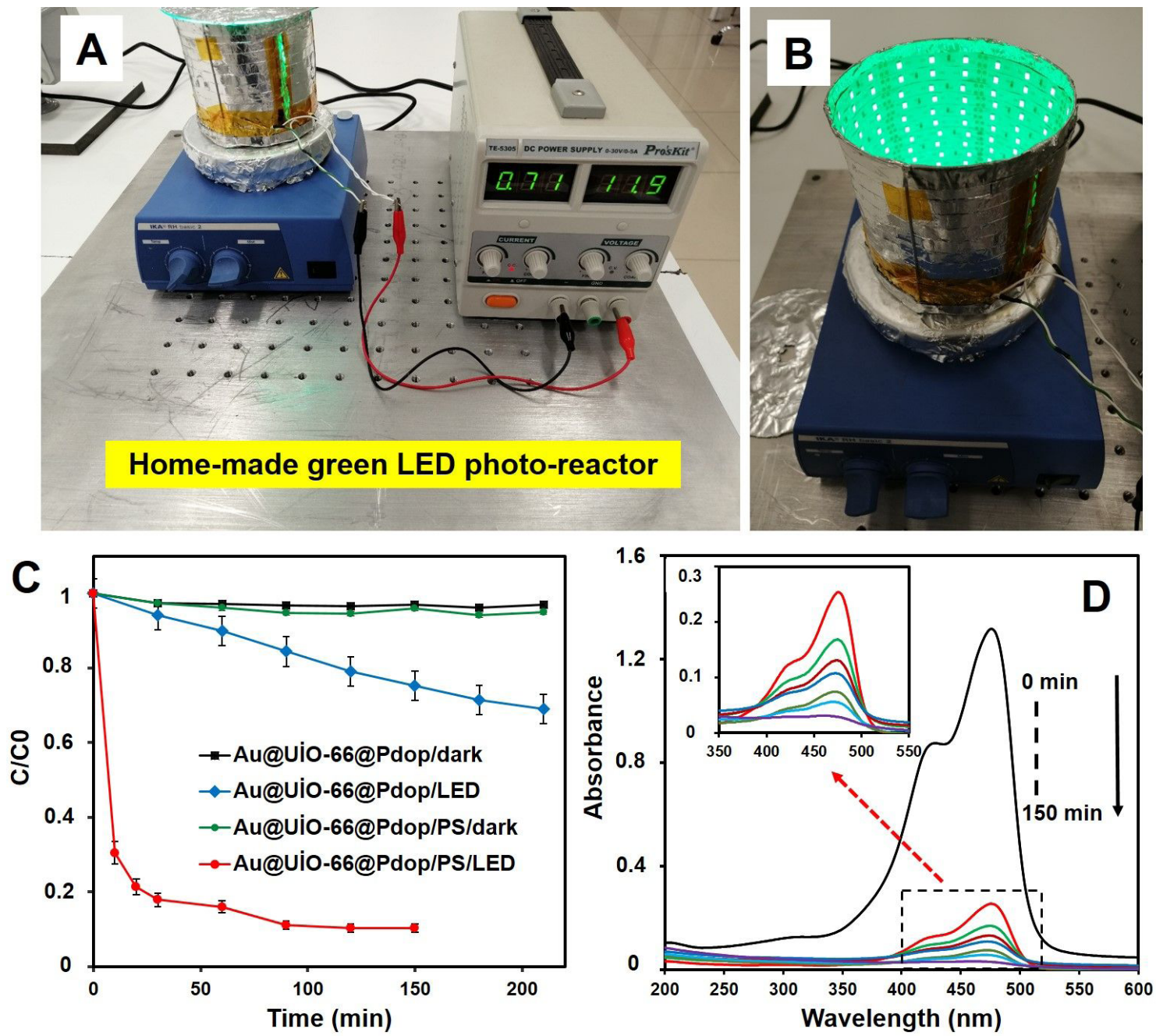

Figure 5. A, B) photographs of the designed home-made green LED photo-reactor, C) The variation of MB concentration (C/CO) and reaction time at different catalytic conditions (Reaction parameters: MB initial concentration: 3.125×10-5 M; Au@UiO-66@Pdop: 20 $\mathrm{mg}$; PS: $2.0 \mathrm{mM}$ ), and D) The changes in the UV-vis spectra of MB during the decolorization process using plasmonic catalyst (Reaction parameters: MB initial concentration: 3.125×10-5 M; Au@UiO-66@Pdop: 20 mg; PS: 2.0 mM).

Figure 3 showed the UV-vis spectra of the aqueous solution of UiO-66@Pdop and Au@Uio-66@Pdop NPs. As seen here, appearance of a new peak around 554 $\mathrm{nm}$ obviously demonstrated the embedding of the Au NPs into the pores of UiO-66@Pdop NPS as well. This peak indicated the localized surface plasmon resonance (LSPR) properties of Au NPs in which no peak was observed around 500-600 nm in the case of UiO-66@ Pdop NPS. Moreover, the related LSPR peak are in good agreement with the obtained EDX results in which the dense elemental composition of the Au NPS were successfully identified.

To recognize the chemical states of the UiO-66@Pdop and Au@UiO-66@Pdop NPs, the XPS analysis technique were employed (Figure 4). As seen here, five main peaks (i.e., O 1s, N 1s, C1s, Zr 3p1, and Zr 3d) related to the binding energies of the UiO-66@Pdop NPs were observed with good intensities (Figure 4A). In Figure $4 B, A u 4 d 3$ and $A u 4 f$ binding energies were supported the presence of Au NPs into the pores of UiO-66@Pdop nanostructures which are in good agreement with EDX and UV-vis results. Note that, embedding of Au NPs via solution impregnation method significantly influenced the XPS results that identified the successful fabrication of the plasmonic Au@UiO-66@Pdop NPs (Figure 4B).

The photocatalytic decolorization of MB was performed to study the photocatalytic performance of Au@UiO-66@ Pdop NPs under green LED light irradiation (Figure 5A, B). For this purpose, the aerobic degradation of $\mathrm{MB}$ was carried out in an aqueous solution $(20 \mathrm{~mL}$ ) containing $20 \mathrm{mg}$ 


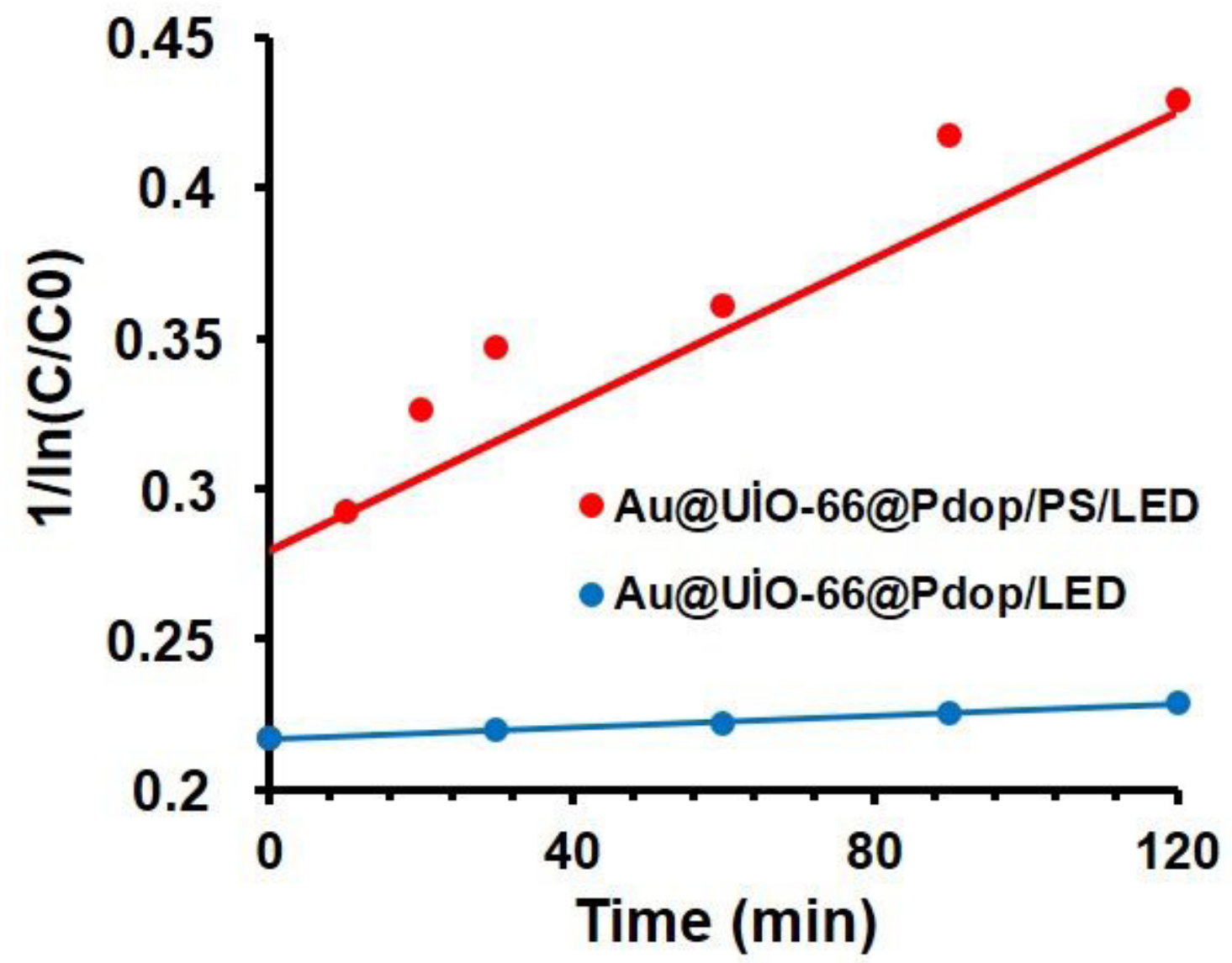

Figure 6. The plots of pseudo-second-order kinetic model for the photocatalytic degradation of MB.

of plasmonic catalyst. Different catalytic conditions were employed to investigate the variations of the $\mathrm{MB}$ concertation (C/CO)/reaction time functions (Figure $5 \mathrm{C})$. As seen here, without light irradiation, no significant degradation was achieved for $210 \mathrm{~min}$, demonstrated that MB was very stable towardAu@UiO-66@Pdop/dark or Au@Uio-66@Pdop/PS/ dark conditions. These two important results clearly showed that plasmonic Au@UiO-66@Pdop NPs neither decolorized the MB solution nor activated the PS and reactive charge carries in dark reaction medium. While in the case of Au@ Uio-66@Pdop/LED, a moderate 31\% bleaching degree was recorded. This value might be attributed to the compatibility between green LED and plasmonic Au@UiO-66@Pdop absorption wavelength (see Figure 3). In order to achieve a reasonable bleaching degree, the fast recombination between photogenerated electron (e-) and hole $(h+)$ pairs must be minimized $[16,19]$. The introduction of PS into photocatalytic reaction medium either increased the performance of Au@ UiO-66@Pdop NPs directly or generated reactive charge carries in which $91 \%$ decolorization of $\mathrm{MB}$ was recorded within 120 min (Figure 5C). Furthermore, PS (i.e., an electron acceptor) inhibited the recombination between photogenerated electron (e-) (i.e., generated electron from Au@uio-66@ Pdop catalyst) and hole $(\mathrm{h}+)$ pairs as well as accelerated the decolorization of MB under LED light irradiation.

The photocatalytic performance of Au@UiO-66@Pdop NPS as well as real-time concentration of MB molecules in the supernatant were measured using the UV-vis spectrometer (Figure 5D). As seen here, the concentration of the MB was sharply decreased under green LED irradiation. After 120 min, approximately $91 \%$ of the MB was bleached which corresponds to the structural changes in the chromophoric groups of the dye molecules [20]. Furthermore, the pseudo-secondorder reaction kinetics of the photocatalysts were calculated and the obtained results were reported in Figure 6. The reaction rate constants related to the bare (Au@Uio-66@Pdop/ LED) and oxidant containing catalyst (Au@Uio-66@Pdop/PS/ LED) are obtained to be 0.0001 and $0.0012 \mathrm{~min}^{-1}$, respectively. These results clearly demonstrated the higher catalytic activity of oxidant containing reaction medium compared to the bare one. 


\section{CONCLUSION}

In summary, plasmonic Au@Uio-66@Pdop NPs were synthesized for efficient decolorization of $M B$ under green LED light irradiation. The catechol groups of the Pdop NPs initiated the Zr (IV) chelate formation in which the organic building blocks started the nucleation of the MOF layer. The physico-chemical analysis of the NPs clearly revealed that stable plasmonic photocatalyst with desired morphology was obtained. A superior and satisfied bleaching degree was achieved thanks to the wavelength compatibility between the irradiated light source as well as good dispersion of the Au@UiO-66@ Pdop NPs in reaction medium. Moreover, the introduction of PS accelerated the decolorization via reducing the charge recombination. The combination between the Au@Uio-66@Pdop NPs and green LED light for visible light degradation of such an organic pollutant could provide the wide range application of the plasmonic MOFs.

\section{Acknowledgments}

This study was partially supported by Ankara Yildirim Beyazit University Scietific Research Unit (Grant No. 4875 and 4736). I would like to thank Mustafa Yasir Aydin for his help with some of the measurements.

\section{References}

1. S. Cao, C.J. Wang, X.J. LV, Y. Chen, W.F. Fu, A highly efficient photocatalytic $\mathrm{H} 2$ evolution system using colloidal CdS nanorods and nickel nanoparticles in water under visible light irradiation, Appl. Catal. B: Environ., 162 (2015) 381-391.

2. T. Baran, S. Wojtyła, A. Dibenedetto, M. Aresta, W. Macyk, Zinc sulfide functionalized with ruthenium nanoparticles for photocatalytic reduction of $\mathrm{CO}_{2}$, Appl. Catal. B: Environ., 178 (2015) 170-176.

3. K. Villa, S. Murcia-López, T. Andreu, J.R. Morante, Mesoporous $\mathrm{WO}_{3}$ photocatalyst for the partial oxidation of methane to methanol using electron scavengers, Appl. Catal. B: Environ., 163(2015) 150-155.

4. C.C. Wang, J.R. Li, X.L. Lv, Y.Q. Zhang, G. Guo, Photocatalytic organic pollutants degradation in metal-organic frameworks, Energy Environ. Sci., 7 (2014) 2831-2867.

5. S. Yuan, L. Feng, K. Wang, J. Pang, M. Bosch, C. Lollar, Y. Sun, J. Qin, X. Yang, P. Zhang, Q. Wang, L. Zou, Y. Zhang, L. Zhang, Y. Fang, J. Li, H.C. Zhou, Stable metal-organic frameworks: design, synthesis, and applications, Adv. Mater., 30 (2018) 1704303.

6. C. Yu, S. Bourrelly, C. Martineau, F. Saidi, E. Bloch, H. Lavrard, F. Taulelle, P. Horcajada, C. Serre, P. L. Llewellyn, E. Magnier, T. Devic, Functionalization of Zr-based MOFs with alkyl and perfluoroalkyl groups: the effect on the water sorption behavior, Dalton Trans., 44 (2015) 19687-19692.
7. C. Wang, G.L. Guo, P. Wang, Synthesis, structure, and luminescent properties of three silver(I) complexes with organic carboxylic acid and 4,4'-bipyridine-like ligands, Transition Met. Chem., 38 (2013) 455-462.

8. C.Y. Sun, S.X. Liu, D.D. Liang, K.Z. Shao, Y.H. Ren, Z.M. Su, Highly stable crystalline catalysts based on a microporous metal-organic framework and polyoxometalates, J. Am. Chem. Soc., 131 (2009) 1883-1888.

9. J.R. Li, J. Sculley, H.C. Zhou, Metal-organic frameworks for separations, Chem. Rev., 112 (2011) 869-932.

10. N.L. Rosi, J. Eckert, M. Eddaoudi, D.T. Vodak, J. Kim, M. O'Keeffe, O. M. Yaghi, Hydrogen storage in microporous metal-organic frameworks, Science, 300 (2003) 1127-1129.

11. A.R. Millward, O.M. Yaghi, Metal-organic frameworks with exceptionally high capacity for storage of carbon dioxide at room temperature, J. Am. Chem. Soc., 127 (2005) 1799817999.

12. C. Wang, P. Wang, L. Feng, Influence of organic carboxylic acids on self-assembly of silver(I) complexes containing 1,2-bis(4-pyridyl) ethane ligands, Transition Met. Chem., 37 (2012) 225-234

13. C.G. Silva, A. Corma, H. Garcia, Metal-organic frameworks as semiconductors, J. Mater. Chem., 20 (2010) 3141,3156.

14. F.X. Llabrés i Xamena, A. Corma, H. Garcia, Applications for metal-organic frameworks (MOFs) as quantum dot semiconductors, J. Phys. Chem., C 111 (2007) 80-85.

15. M.C. Das, H. Xu, Z. Wang, G. Srinivas, W. Zhou, Y.F. Yue, V.N. Nesterov, G. Qian, B. Chen, A Zn O-containing doubly interpenetrated porous metal-organic framework for photocatalytic decomposition of methyl orange, Chem. Commun., 47 (2011) 11715-11717.

16. Y. Gao, S. Li, Y. Li, L. Yao, H. Zhang, Accelerated photocatalytic degradation of organic pollutant overmetal-organic framework MIL-53(Fe) under visible LED lightmediated by persulfate, Appl. Catal. B Environ., 202 (2017) 165-174.

17. K. Ai, Y. Liu, C. Ruan, L. Lu, G. Lu, Sp² C-Dominant N-Doped Carbon Submicrometer Spheres with Tunable Size: A Versatile Platform for Highly Efficient Oxygen Reduction Catalysts, J. Adv. Mater., 25 (2013) 998-1003.

18. M. Zhao, C. Deng, X. Zhang, The design and synthesis of a hydrophilic core- shell-shell structured magnetic metalorganic framework as a novel immobilized metal ion affinity platform for phosphoproteome research, Chem. Commun., 50 (2014) 6228-6231.

19. J.J. Du, Y.P. Yuan, J.X. Sun, F.M. Peng, X. Jiang, L.G. Qiu, A.J. Xie, Y.H. Shen, J.F. Zhu, New photocatalysts based on MIL53 metal-organic frameworks for the decolorization of methylene blue dye, J. Hazard. Mater., 190 (2011) 945-951.

20. B. Paul, B. Bhuyan, D.D. Purkayastha, M. Dey, S.S. Dhar, Green synthesis of gold nanoparticles using Pogestemon benghalensis (B) O. Ktz. leaf extract and studies of their photocatalytic activity in degradation of methylene blue, Mater. Lett., 148 (2015) 37-40. 